\title{
PARA UM RETORNO GENEALÓGICO AO DIREITO: SOBRE A PASSAGEM DAS SOCIEDADES ARCAICAS PARA UMA SOCIEDADE RELIGIOSAMENTE CAPITALISTA
}

Henrique Garbellini Cárnio

Mestrando em Filosofia do Direito pela Pontifícia Universidade Católica de São Paulo- PUC/SP. Bolsista do Centro de Aperfeiçoamento de Pessoal de Nível Superior (CAPES)

henriquegarbellini@yahoo.com.br

\section{RESUMO}

O Direito enquanto criação humana, produto da linguagem, imprescindivelmente precisa de uma reflexão genealógica, que se volte às origens dos seus obscuros sentidos. Esse regresso possibilita um resgate para uma construção do próprio Direito. A análise das sociedades arcaicas em suas relações de trocas identifica já um sentido jurídico e um paradigma social que existiu e de outras maneiras ainda é existente, no entanto, diferente da atual sociedade em que vivemos, uma sociedade re(produzida) de maneira religiosamente capitalista. Essa compreensão enseja um posicionamento também diferente em relação ao Direito e a Justiça.

Palavras-chave: Genealogia do Direito; sociedades arcaicas, sociedade religiosamente capitalista.

\begin{abstract}
Title: Towards a genealogical Return to Law: Concerning the Passage From Archaic Societies to a Religiously Capitalist Society.

The Law as human creation, a product of language, certainly needs a genealogical reflection that goes back to the origins of its obscure senses. This return permits a rescue of the building of Law itself. The analysis of archaic societies in their exchanging relations already identifies a juridical sense and a social paradigm that existed and still exists in other ways. Nevertheless, it's different from the current society in which we live, a society re(produced) in a religiously capitalist way. This understanding also creates a different position concerning Law and Justice.
\end{abstract}

Key-words: Law Genealogy, archaic societies, religiously capitalist society. 


\section{INTRODUÇÃO}

Uma busca genealógica sobre o sentido da vivência humana hodiernamente, que possibilite uma nova atitude em si própria se afigura como uma das questões mais importantes, mais suscitantes para os homens e todas as suas criações, atitude essa que pode ser ilustrada com uma frase enigmática do contemporâneo filósofo italiano Giorgio AGAMBEN: “qualquer improfanável baseia-se no aprisionamento e na distração de uma intenção autenticamente profanatória. Por isso é importante toda vez arrancar dos dispositivos - de todo dispositivo - a possibilidade de uso que os mesmos capturaram. A profanação do improfanável é a tarefa política da geração que vem”1 .

O ambiente dessa profanação se insere numa perspectiva de percepção avassaladora, o ser humano criador de mundo, nele lançado, que projeta-o se projetando, faz do seu projetar destruição, o aniquilamento do próprio mundo. Esta dualidade criação-destruição é distinta da formação do conhecimento, do próprio sentido de constância, de permanência da criação que necessita da destruição, é uma destruição física do próprio mundo, no qual, anteriormente, portanto, já se convalesceu para a maioria dos homens a não reflexão da complexa ambivalência vivencial (experencial/existencial) na qual estão inseridos.

Várias indagações surgem a partir desta observação e possibilitam o delineamento para indicar sem efusivas pretensões, algumas razões para esta constatação, o sentido do verbo profanar se faz bastante claro, no caso, se deve profanar aquilo que é ou se apresenta como sagrado.

O primeiro ponto do lineamento para se reconhecer a necessidade de uma (re)torno genealógico surge da acertada análise de Walter BENJAMIN que reconhece no capitalismo uma religião, em verdade a frase enigmática a que se aludiu se apresenta justamente como reflexão a partir deste texto: Kapitalismus als Religions (Capitalismo como religião) ${ }^{2}$.

Como reflexão pari passu no sentido da profanação que se está buscando surge também uma importante passagem de uma das duas mais conhecidas obras de Karl MARX: $O$ Manifesto Comunista na qual o autor reconhece que: "tudo o que é sólido se desmancha no $\mathrm{ar}^{3}$, tudo o que é sagrado é profanado, e os homens são finalmente forçados a enfrentar com

\footnotetext{
${ }^{1}$ AGAMBEN, Giorgio. Profanações. Tradução de Selvino J. Assmann. São Paulo: Boitempo, 2007, p. 79.

2 Este é um dos documentos inéditos de Walter Benjamin [1892-1940] publicados em 1985 por Ralph Tiedemann e Hermann Schweppenhäuser no volume 6 de "Gesammelte Schriften" (Suhrkamp Verlag), um texto denso que por não se destinar à época para publicação possui um conteúdo pesado e possibilita ampla relfexão.Cf. BENJAMIN, Walter. Gesammelte Schriften. Frankfurt/Main: Suhrkamp, 2001.

${ }^{3}$ Esta primeira frase fui muito bem usada como título de uma obra muito interessante sobre os efeitos da modernidade por Marshall Berman. Portanto nesse sentido Cf. BERMAN, Marshall. Tudo o que é sólido
} 
sentidos mais sóbrios suas reais condições de vida e sua relação com outros homens.”. De fato a denúncia de MARX prenuncia no revolucionar da produção o caminho humano para a adoração religiosa do capitalismo ${ }^{4}$.

O segundo ponto do lineamento passa então a ter importância, para se compreender essa devoção religiosa ao capitalismo, é preciso que se tenha consciência da amplitude de seus efeitos, efeitos que tomam conta das criações dos homens. Vivemos numa sociedade onde há os que podem muito e que mesmo assim nada fazem, tudo é manipulado ou se manipula diante de uma consciência religiosamente exercida capitalisticamente.

O intuito, portanto, é não ingenuamente criticar o capitalismo e seus efeitos, pois dessa ingenuidade ele facilmente já se adaptou, mas sim propor um busca genealógica, partindo das sociedades primitivas que viviam um paradigma diferente e, portanto, uma vida diferente, e procurar assim, não resolver o problema, mas incitar sua reflexão, do porque desta passagem das sociedades antigas para a nossa e o quanto ela está colocando em risco o próprio homem, um risco além da alienação, o risco da extinção.

Assim, como extensão do estudo a proposta se completa com a abordagem ao mesmo tempo genealógica de uma das grandes criações dos homens, o Direito, que poderá ser alçada diretamente, pois, nas sociedades antigas seu estabelecimento se dava entre os contratos e as trocas entre os homens e deuses, um fenômeno mais que jurídico, mas, ainda sim jurídico.

\section{PARA UMA (RE)TORNO GENEALÓGICO: O DOM: A TROCA NAS SOCIEDADES ARCAICAS.}

No célebre Ensaio sobre o dom (Essai sur le don) de 1924, Marcel MAUSS descobria a organização das sociedades arcaicas regidas por sistemas sociais-totais estruturados sobre uma regra social primordial, a tríplice obrigação de dar, receber e retribuir.

Dar, receber e retribuir era a base organizacional das sociedades arcaicas, era preciso por em circulação os presentes e os benefícios, ou, até mesmo os malefícios.

O primeiro ponto a se chamar atenção nessas sociedades surge do entendimento do estabelecimento dessa tríplice obrigação, ou seja, o que regia estas sociedades era o caráter da

desmancha no ar: a aventura da modernidade. Tradução de Carlos Felipe Moisés e Ana Maria L. Ioriatti. São Paulo: Cia das Letras, 2001.

${ }^{4}$ Em que pese a crítica que na seqüência será exposta no texto de BENJAMIN sobre como MARX teria contribuído para esta "religião" capitalista, a passagem é clara sobre o sentido de profanação que surge ao homem e que deve por ele ser feita, sob pena de além de a si próprio se enganar, alienar, atualmente, proporcionar a própria destruição do mundo em que vive. 
troca e nessa relação contratual se misturavam as almas nas coisas, o que MAUSS, identifica precisamente para manter o termo utilizado pelas sociedades arcaicas como potlatch ${ }^{5}$.

O potlatch é bem mais que um fenômeno jurídico, ele é o sistema da dádiva das trocas que possui originariamente o sentido jurídico contratual da relação que ali se formava, a partir de uma regra de Direito. A tríplice obrigação, era de fato, algo definitivamente obrigacional, a essência dessa obrigação era seu início, dar, ao passo em que se dava e ao mesmo tempo na coisa se misturava o espírito da pessoa era preciso recebê-la, não podendo recusá-la e então retribuir, o retribuir é todo o potlatch.

Nota-se assim, certa complexidade nessa relação que passa a propiciar a (sobre)vivência destas sociedades. O mais interessante é que a relação social nelas não fluía segundo os parâmetros do mercado ou do contrato, na verdade o mais importante nessa produção de vida não era simplesmente a satisfação utilitária e efetiva dos membros da sociedade, o que importava em primeiro lugar era constituir o laço social, essa é a afirmação do dom.

A sociedade se estruturava pelo vínculo da dádiva, a partir de uma análise acurada do Ensaio de MAUSS, Alain CAILLÉ, observa a maneira ritual que se formava a obrigação numa mistura inextrincável de interesse e desinteresse.

É que a pessoa que dá não é capaz de satisfazer seu interesse próprio a não ser pelo rodeio da satisfação do interesse do outro - de seguir o seu desejo próprio a não ser se submetendo à lei do desejo do outro - e, de modo mais geral, a não ser observando a regra do dom que postula, de maneira lógica, que a relação deve ser construída pelos indivíduos que nele entram antes que estes possam tirar proveito dela. ${ }^{6}$

A análise de CAILLÉ se aprofunda no reconhecimento de que a tríplice obrigação de dar, receber e retribuir, constitui “o universal sócio-antropológico sobre o qual foram construídas as sociedades antigas e tradicionais" ${ }^{7}$, ela foi o alicerce do que se pode designar de sociedade primeira, afirmando que MAUSS já esboçava originariamente “precisamente uma genealogia empírica da moral, da justiça e do político.”8 ${ }^{\text {. }}$

A reflexão sobre o dom proporciona o entendimento da importância do quanto esse estudo genealógico é crucial em nossos $\operatorname{dias}^{9}$ sob dois aspectos; primeiro compreender

\footnotetext{
${ }^{5}$ Cf. MAUSS, Marcel. Sociologia e antropologia. São Paulo: Cosac e Naify, 2003, p. 235.

${ }^{6}$ CAILLÉ. Alain. Antropologia do dom: o terceiro paradigma. Tradução de Ephraim Ferreira Alves. Petrópolis: Editora Vozes, 2002, p. 8.

${ }^{7}$ Ibidem, p. 9.

${ }^{8}$ Ibidem, p. 9.

${ }^{9}$ Sobre os própositos de Alain Caillé na obra referida, importante ressaltar que ele reconhece no dom um terceiro paradigma. Sua proposta se inicia explicando a idéia de paradigma iniciando pela abordagem bastante conhecida de Thomas Kuhn e passa a identificar três paradigmas, o terceiro seria justamente o paradigma do dom, mais acertado que os outros dois primeiros (o primeiro individualista o segundo holista), em suas palavras "o
} 
que juntamente com a circulação de bens e serviços nos mercados, a circulação garantida pelo Estado sob a forma de redistribuição, há consideravelmente um grande número de relações que transitam através dos mecanismos do dom e do contrato, a sociedade moderna se encontra com a sociedade primeva ao passo em que até mesmo possibilita novas formas de dom que vêm compensar, sem muita ênfase, a frieza da lógica mercadológica. Tal análise se encontra na perspectiva traçada por Jacques T. GODBOUT, na obra $O$ espírito do dom. O segundo aspecto, que é o que mais nos interessa para a presente reflexão, é compreender o sentido originário das sociedades primitivas para incitar indagações do porque e do como dessa passagem, dessa transformação, que atualmente vivemos, de sociedades que viviam a partir de uma tríplice obrigação para uma sociedade que é governada devotamente pelas relações de mercado, portanto, esta reflexão em termos genealógicos se inicia também com a busca para se resgatar o sentido perdido com o passar do tempo de valores esquecidos que se pode perceber pela própria atuação humana neste mundo criado e constantemente modificado (desumanizado, destruído) por seus criadores.

\section{A PASSAGEM: O CAPITALISMO RELIGIOSAMENTE EXERCIDO.}

A constatação da formação primeva da sociedade e dos sentidos da magia e da religião nos contornos sociais possibilita uma reflexão ainda maior sobre a atual atribulada vivência em sociedade.

O ponto de exploração dessa reflexão se inicia a partir de dos documentos inéditos de Walter BENJAMIN publicados em 1985 por Ralph Tiedemann e Hermann Schweppenhäuser no volume 6 de "Gesammelte Schriften" (Suhrkamp Verlag), um texto denso que por não se destinar à época para publicação possui um conteúdo pesado e especificamente importante para o entendimento do escopo maior deste estudo ${ }^{10}$.

paradigma do dom não pretende exatamente analisar como se gera o vínculo social nem a partir da base - a partir dos indivíduos sempre separados - nem a partir do alto - a partir de uma totalidade social através e sempre já presente aí - mas de algum modo a partir do seu meio, horizontalmente, em função do conjunto das interrelações que ligam os indivíduos e os transformam em atores propriamente sociais...em muitas sociedades arcaicas, talvez em toda parte, é rivalizando em dons que os seres humanos se ligam e constituem sociedade, trocando bens que não possuem um valor utilitário mas simbólico, é também porque, desde há muito, ele tinha ao mesmo tempo generalizado e radicalizado a idéia durkheimiana segundo a qual "a vida social não é possível a não ser por um vasto simbolismo", e os símbolos, segundo as palavras de Claude Lévi-Strauss, são "mais reais que aquilo que simbolizam”"'. CF. CAILLÉ, Alain, op. cit. pp. 19 e 20. Na verdade, Mauss vai além desta questão do simbolismo tratada por seu tio Durkheim e por Lévi-Strauss, ele reconhece a instância do simbolismo, mas aprofunda seus estudos no sentido vivencial destas sociedades o que permite identificar o verdadeiro sentido originário das sociedades, que não é meramente simbólico.

${ }^{10}$ Cf. BENJAMIN, Walter. Kapitalismus als Religion in Gesammelte Schriften. Frankfurt/Main: Suhrkamp, 2001, pp. 101/103. 
A proposta de BENJAMIN neste texto parece ser inspirada por Max WEBER em seu texto A Ética Protestante e o Espírito do Capitalismo, contudo BENJAMIN vai além de WEBER, apresentada uma crítica cabal e anticapitalista.

O texto começa com a seguinte afirmação "no capitalismo pode se ver uma religião”11 que se segue da superação, já mencionada, da proposta de WEBER.

A prova desta estrutura religiosa do capitalismo não está apenas como pensava Weber no fato de que ela tem uma constituição condicionada de maneira religiosa, mas sim, como no fato de ser um aparecimento essencialmente religioso, isto levaria hoje, ainda, ao caminho equivocado de uma polêmica universal sem medidas. Nós não podemos perceber a rede na qual estamos presos ${ }^{12}$.

Consequentemente, considerando a possibilidade de uma polêmica universal se medida, entretanto, BENJAMIN reconhece três pontos desta estrutura religiosa do capitalismo.

\subsection{O Culto.}

O primeiro ponto é o culto, ou seja, o capitalismo se apresenta como uma religião puramente cultual.

Primeiro o capitalismo mostra-se como uma religião puramente cultual, talvez a mais extrema que algum dia existiu. Para ele tudo só tem significado na sua relação imediata com o culto, ele não conhece nenhuma dogmática especial, nenhuma teologia. O utilitarismo ganha sob esse ponto de vista a sua coloração religiosa ${ }^{13}$.

A partir dessa passagem, nota-se que as práticas utilitárias do capitalismo, desde investimento de capitais até a compra e venda de mercadorias possuem um sentido de culto religioso e o que as permite serem assemelhadas a um culto se apresenta com um exemplo no texto sobre o dinheiro como objeto de um culto análogo aos santos das religiões comuns: "Faça se um confronto entre as imagens sagradas das diversas religiões por um lado e as cédulas de dinheiro dos mais diversos estados por outro. O espírito que fala através dos ornamentos destas cédulas.”14.

3.2 A permanência do culto: sem trégua e sem peidade.

\footnotetext{
${ }^{11}$ A tradução do texto se refere ao original em alemão da obra Gesammelte Schriften pela ed. Suhrkamp, publicado em 2001, feito pelo prof. Dr. Willis Santiago Guerra Filho, de maneira que ficam desde já reconhecidos o nosso apreço e agradecimento. Este texto num primeiro momento foi traduzido para ser discutido nas aulas ministradas na matéria de Filosofia do Direito II (Bases mítico-religiosas do Direito) na Pontifícia Universidade Católica de São Paulo (PUC/SP) no segundo semestre de 2007.

${ }^{12}$ BENJAMIN, op cit., p. 100.

${ }^{13}$ Ibid., p. 100.

${ }^{14}$ Ibid., p. 102.
} 
O segundo ponto que estabelece BENJAMIN é a duração permanente do culto que está estreitamente ligada a essa concreção do culto, “a esta concreção do culto, está relacionado um segundo aspecto do capitalismo: a duração permanente do culto. O capitalismo é a celebração de um culto sans revê et san merci. Ali não há nenhum dia da semana, pois não há um dia que não seja dia de festa” ${ }^{15}$.

Esta celebração de um culto sem sonho, sem piedade, sem trégua se apresenta no cotidiano humano das fábricas e das oscilações das operaçõpes mercantis, que provocam uma tensão e estafa mental que leva o homem a ser este ser incorporado religiosamente por este sentido de vida.

As práticas capitalistas não cessam, o próprio descanso para alguns trabalhadores é condicionado justamente como um complemento do culto.

\title{
3.3 Sem expiação e com culpa.
}

Por último e enfim, a terceira característica do capitalismo como religião é a sua culpabilização.

\begin{abstract}
O capitalismo é provavelmente o primeiro caso de um culto que não é expiatório, que não é, portanto, um culto para purgar a culpa, mas sim um culto de culpabilização. E com isso mostra-se este sistema religioso na balada de um movimento horrível, um sentimento de culpa terrível que não se deixa desculpar. Apega-se ao culto não para que nele possa purgar a culpa, mas sim para tornar universal a consciência impregnada pela culpa e por fim e acima de tudo envolver Deus mesmo nesta culpa ${ }^{16}$.
\end{abstract}

A questão que envolve todo essa culpabilização é a eternidade da culpa, quanto mais se compra mais se deve, razão esta a dominação religiosa do capitalismo, além de qualquer outra religião.

Além da identificação destas características do capitalismo BENJAMIN levanta uma crítica bastante relevante e incitante sobre três importantes pensadores: Nietzsche, Freud e Marx.

A transcendência de Deus caiu, mas ele não está morto, ele foi envolvido no destino humano. Esta passagem do planeta humano através da casa do desespero, na qual a solidão absoluta de seu caminho é o ethos que Nietzsche indicou, este homem é o super-homem, o além do homem, o primeiro que reconheceu e começou a cumprir a religião capitalista, corresponder a ela... A teoria freudiana também pertence ao sacerdócio deste culto, ela foi totalmente pensada capitalisticamente. O recalque, a consciência culpada é profundamente entendida em analogia com o capital, do qual

\footnotetext{
${ }^{15}$ Ibid., p. 100.

${ }^{16}$ Ibid., p. 100.
} 
cobram juros do inferno do inconsciente...Da mesma maneira em Marx: o capitalismo sem retorno tornou-se com os juros e juros sobre juros, enquanto tais, funções da culpa (schuld) (veja o duplo sentido demoníaco deste termo) ${ }^{17}$. Também para Marx na sua concepção do capitalismo com juros e juros sobre juros enquanto função de uma divida que também é uma culpa ele se torna socialista. O capitalismo é uma religião do culto puro sem dogma ${ }^{18}$.

BENJAMIN é enfático nas críticas que tece, de certa maneira o ambiente teórico a que se refere demonstra uma prática do capitalismo totalmente mordaz às análises filosóficas, sociológica e psicológicas. O capitalismo é produtor de desespero, a culpa dos humanos e seu endividamento para com o capital de maneira constante, daí a impossibilidade da expiação, a única salvação da religião da capital é a própria intensificação do sistema, o que faz agravar o desespero e aprimorar o culto ${ }^{19}$.

Enfim, esta prática religiosa se consagra socialmente e repercute intimamente nos indivíduos, "antes indivíduos irreligiosos ou de outras crenças de sua comunidade era visto exatamente no sentido de um falso membro, como a atual burguesia vê os membros da sociedade que não são produtivos.”20.

Reconhecer no capitalismo uma religião já é uma forma de profaná-lo, ocorre que devido à sua extensão religiosa resta-nos agora buscar argumentos para os "dispositivos de desarmamento" desta operação religiosa que deve se iniciar teoricamente de maneira individualizada, sem provocar como o próprio BENJAMIN se referia uma polêmica universal desmedida.

A individualização, neste sentido, requer o reconhecimento dos atordoamentos religiosos do capitalismo e o entendimento de que estamos por ele tomados.

Como continuidade às reflexões de BENJAMIN, o filósofo italiano Giorgio AGAMBEN apresenta uma interessante perspectiva, para ele o capitalismo, levando ao extremo uma tendência já presente ao cristianismo, generaliza e absolutiza, em todo âmbito, a estrutura da separação que define a religião ${ }^{21}$.

O capitalismo de maneira religiosa parece ir além e ser indiferente da cisão sagrado/profano, divino/humano, ele a pura forma de separação, sem mais nada a separar.

\footnotetext{
${ }^{17}$ Nota da tradução a que nos referimos: Em alemão a palavra schuld quer dizer tanto a palavra dívida como a palavra culpa.

${ }^{18}$ Ibid., pp. 101/102.

${ }^{19}$ Sobre o texto, muito relevante é o que retratou Michel LÖWY em uma conferência na USP na cidade de São Paulo com versão traduzida por Luiz Roberto Mendes Gonçalves, Publicado em: Folha de São Paulo, Caderno Mais, domingo, 18 de setembro de 2005.

${ }^{20}$ Ibid., p. 103.

${ }^{21}$ Cf. AGAMBEN, Giorgio op. cit., p. 71.
} 
E como, na mercadoria, a separação faz parte da própria parte da própria forma de objeto, que se distingue de valor de uso e valor de troca e se transforma em fetiche inapreensível, assim agora tudo o que é feito, produzido e vivido - também o corpo humano, também a sexualidade, também a linguagem - acaba sendo dividido por si mesmo e deslocado para uma esfera separada que já não define nenhuma divisão substancial e na qual todo uso se torna duravelmente impossível. Esta esfera é o consumo. Se conforme foi sugerido, denominamos a fase extrema do capitalismo que estamos vivendo como espetáculo, na qual todas as coisas são exibidas na sua separação de si mesmas, então espetáculo e consumo são as duas faces de uma única impossibilidade de usar. $^{22}$

A questão então se estreita, AGAMBEN continua a reflexão, no sentido de se profanar significa restituir ao uso comum o que havia sido separado na esfera do sagrado, a religião capitalista está voltada para a criação da algo absolutamente improfanável. Os objetos ao receberem o exercício do direito de propriedade provacam a infelicidade dos consumidores, porque eles se tornaram incapazes de os $\operatorname{profanar}^{23}$.

\section{O DIREITO E A JUSTIÇA NA ESFERA DO SAGRADO E DO PROFANO: O APROVEITAMENTO GENEALÓGICO.}

Compreender o sentido jurídico, como se expôs, na esfera originária das sociedades primitivas é delimitar um ponto para uma reflexão sobre o Direito.

Esse reflexão, portanto, de maneira mais direcionada, pode se dar no contorno do campo (meta)ético do Direito, em relação ao conceito de justiça.

NIETZSCHE na segunda dissertação da obra Genealogia da Moral ${ }^{24}$, explora de certa maneira o conteúdo genealógico do Direito.

Antes ainda dessa obra, há uma importante passagem na obra Humano, demasiado humano, que serve como ponto de partida para o que se propõe.

Nessa obra, NIETZSCHE, no aforismo 92 se refere a origem da justiça ${ }^{25}$, nos seguintes termos.

Origem da justiça. A justiça (equidade) tem origem entre homens aproximadamente o mesmo poder[...]: troca é o caráter inicial da justiça. Cada um satisfaz ao outro, ao receber aquilo que estima mais que o outro. Um dá ao outro o que ele quer, para têlo como seu a partir de então, e por sua vez recebe o desejado. A justiça é, portanto,

\footnotetext{
22 Ibid., p. 71.

${ }^{23}$ Ibid., pp. 72/73.

${ }^{24}$ NIETZSCHE, Friedrich. Genealogia da moral. Tradução de Paulo César de Souza. São Paulo: Companhia das Letras, 2007.

${ }^{25}$ Evitando qualquer desentendimento no sentido da proposta filosófica que proponho, em relação a um sentido metafísico da concepção nietzscheana, importante ressaltar a seguinte passagem de Martin Heidegger a partir do seguinte comentário "Nevertehless, because in Nietzsche's thought it remains veiled as to whether and how "justice" is te essencial trait of truth, the key word justice may not be raised to the rank of the main heading in Nietzsche’s metaphysics”. CF. HEIDEGGER, Martin. Nietzsche: vol. 3. San Francisco: Harper Collins pbk, 1991, p. 249.
} 
retribuição e intercâmbio sob o pressuposto de um poderio mais ou menos igual: originalmente a vingança pertence ao domínio da justiça, ela é um intercâmbio. Do mesmo modo a gratidão ${ }^{26}$.

Esse conceito originário de justiça, muito tem a ver com o sentido de identificação jurídica das relações de troca das sociedades arcaicas entendidas no viés proposto por Marcel MAUSS, que se apresenta ainda com maior repercussão na continuidade na obra Genealogia da Moral na refutação da obra de Eugen DÜHRING.

A questão crucial que torna NIETZSCHE importante neste contexto é o sentido reconstituidor em relação à pré-história da humanidade baseada em conceitos com conteúdos jurídicos.

Para NIETZSCHE esse sentido de reconstituição da pré-história da humanidade “ou seja, do próprio processo de humanização - que tem início com a criação da memória - ocorre num contexto completamente determinado por conceitos e categorias jurídicas, sendo predominantemente dominado pela ancestral obligatio de direito pessoal vigente nos atos de escambo e da troca, do débito e do crédito" 27 .

Esse é o ponto de junção de toda a reflexão do estudo: proposta de MAUSS em relação as trocas nos sociedades e a crença, compreensão da força desse conceito de dívida, débito, culpa (schuld) ${ }^{28}$ bem demonstrado por BENJAMIN e a própria proposta de NIETZSCHE em relação ao sentido originário do processo de humanização.

Para NIETZSCHE, na verdade não há uma justiça em si e como refutação de DÜHRING, a justiça não se dá nos moldes da vingança.

Na segunda dissertação, § 8 de sua Genealogia da moral, NIETZCHE assim se refere: "Cada coisa tem seu preço; tudo pode ser pago - o mais velho e ingênuo cânon da justiça[...]nesse primeiro estágio, a justiça é boa vontade, entre homens de poder aproximadamente igual, de acomodar-se entre si, de entender-se mediante compromisso - e, com relação aos de menor poder, força-los a um compromisso entre si”29.

\footnotetext{
${ }^{26}$ NIETZSCHE, Friedrich. Humano, demasiado humano. Tradução de Paulo César de Souza. São Paulo: Companhia das Letras, 2005, p. 65.

${ }^{27}$ GIACOIA JUNIOR, Oswaldo. Nietzsche e a genealogia do direito in Crítica de modernidade: diálogos com o direito. Ricardo Marcelo Fonseca (org.). Florianópolis: Fundação Boiteux, 2005, pp. 23/24.

${ }^{28}$ Extremamente valiosa nesse sentido a contribuição de Émile Benveniste em relação aos conceitos de dádiva e troca e crédito e crença nos seus sentidos originários. Para tanto, cf. BENVENISTE, Émile. O vocabulários das instituições indo-européias: I. economia, parentesco, sociedade. Tradução de Denise Bottman. Campinas: Editora da UNICAMP, 1995, pp. 63/88 e pp. 171/178, respectivamente.

${ }^{29}$ NIETZSCHE, Friedrich. Genealogia da moral. Tradução de Paulo César de Souza. São Paulo: Companhia das Letras, 2007, p. 60.
} 
Essa afirmação de NIETZSCHE retorna ao sentido da vinculação de credor e devedor nas formas mais rudimentares de direito pessoal, nas relações de troca, contrato, dívida, direito e obrigação e os obscuros começos de justiça ${ }^{30}$.

Portanto, o que NIETZSCHE está a descobrir nesse entrecruzemento entre obligatio de Direito pessoal e os conceitos de barbárie e castigos primitivos será mais tarde “o apanágio da sociabilidade e da moralidade, tais as categorias fundamentais do imaginário religioso, como também a noção moral de culpa, o sentimento de dever, a consciência da responsabilidade e da autonomia” ${ }^{31}$.

Enfim, explorar o sentido originário do sentido jurídico nas sociedades primitivas em correlação com a sociedade que se instaura hodiernamente, como o afastamento do conceito de justiça divina e virtuosa ${ }^{32}$ que se encaminha entre outras coisas para a vingança, possibilita um resgate de muitos outros sentidos esquecidos e perdidos em todo esse caminho histórico, resgatar é muito importante para o Direito, pois como criação humana e produzido pela linguagem o Direito tem como sua grande potencialidade e responsabilidade uma função social de um próprio resgate da sociedade.

\section{BIBLIOGRAFIA.}

AGAMBEN, Giorgio. Profanações. Tradução de Selvino J. Assmann. São Paulo: Boitempo, 2007.

BENJAMIN, Walter. Kapitalismus als Religions in Gesammelte Schriften. Frankfurt/Main: Suhrkamp, 2001.

BENVENISTE, Émile. O vocabulário das instituições indo-européias: I. economia, parentesco, sociedade. Tradução de Denise Bottman. Campinas: Editora da UNICAMP, 1995.

BERMAN, Marshall. Tudo o que é sólido desmancha no ar: a aventura da modernidade. Tradução de Carlos Felipe Moisés e Ana Maria L. Ioriatti. São Paulo: Cia das Letras, 2001.

CAILLÉ. Alain. Antropologia do dom: o terceiro paradigma. Tradução de Ephraim Ferreira Alves. Petrópolis: Editora Vozes, 2002.

\footnotetext{
${ }^{30}$ Cf. GIACOIA JUNIOR, op cit p. 28.

${ }^{31}$ Ibid., p. 30.

32 Muito importante, nesse sentido a análise de BENVENISTE sobre os termos Thémis e Diké como se relacionam e são portadores do sentido tanto divino quanto de virtude do início do conceito de Direito (justiça) que aqui não se retratou, pois é tema que deve merecidamente ser visto em separado e que se encontra presente nas minhas atuais reflexões. Cf. BENVENISTE, Émile. O vocabulário das instituições indo-européias. Tradução de Denise Bottman, Campinas: Ed. Unicamp, 1995.
} 
GIACOIA JUNIOR, Oswaldo. Nietzsche e a genealogia do direito in Crítica da modernidade: diálogos com o direito. Ricardo Marcelo Fonseca (org.). Florianópolis: Fundação Boiteux, 2005.

HEIDEGGER, Martin. Nietzsche: vol. 3. San Francisco: Harper Collins pbk, 1991.

MAUSS, Marcel. Sociologia e antropologia. São Paulo: Cosac e Naify, 2003.

NIETZSCHE, Friedrich. Genealogia da moral. Tradução de Paulo César de Souza. São Paulo: Companhia das Letras, 2007.

Humano, demasiado humano. Tradução de Paulo César de Souza. São Paulo: Companhia das Letras, 2005. 